\title{
Biological treatment for psoriasis and the risk of herpes zoster: results from the Psoriasis Longitudinal Assessment and Registry (PSOLAR)
}

Guy Shalom, Luigi Naldi, Mark Lebwohl, Arjen Nikkels, Elke M. G. J. de Jong, Steven Fakharzadeh, Kavitha G. Goyal, Bhaskar Srivastava, Wayne Langholff, Claudia Galindo \& Arnon D. Cohen

To cite this article: Guy Shalom, Luigi Naldi, Mark Lebwohl, Arjen Nikkels, Elke M. G. J. de Jong, Steven Fakharzadeh, Kavitha G. Goyal, Bhaskar Srivastava, Wayne Langholff, Claudia Galindo \& Arnon D. Cohen (2019) Biological treatment for psoriasis and the risk of herpes zoster: results from the Psoriasis Longitudinal Assessment and Registry (PSOLAR), Journal of Dermatological Treatment, 30:6, 534-539, DOI: 10.1080/09546634.2018.1445193

To link to this article: https://doi.org/10.1080/09546634.2018.1445193

Accepted author version posted online: 05 Apr 2018

Published online: 06 Jun 2019.

Llll Article views: 288

View Crossmark data
Submit your article to this journal $\square$

Q View related articles ๔

Citing articles: 3 View citing articles 


\title{
Biological treatment for psoriasis and the risk of herpes zoster: results from the Psoriasis Longitudinal Assessment and Registry (PSOLAR)
}

\author{
Guy Shalom ${ }^{a}$, Luigi Naldi ${ }^{b}$, Mark Lebwohl' ${ }^{c}$, Arjen Nikkels ${ }^{d}$, Elke M. G. J. de Jong ${ }^{e}$, Steven Fakharzadeh ${ }^{f}$, \\ Kavitha G. Goyal ${ }^{\mathrm{g}}$, Bhaskar Srivastava ${ }^{\mathrm{g}}$, Wayne Langholff ${ }^{\mathrm{f}}$, Claudia Galindo ${ }^{\mathrm{f}}$ and Arnon D. Cohen ${ }^{\mathrm{h}, \mathrm{i}}$
}

\begin{abstract}
${ }^{a}$ Department of Dermatology and Venereology, Soroka Medical Center, Beer-Sheva, Israel; ${ }^{b}$ Department of Dermatology, Azienda Ospedaliera Papa Giovanni XXIII, Study Center of the Italian Group for Epidemiologic Research in Dermatology (GISED), Bergamo, Italy; 'Icahn School of Medicine at Mount Sinai, New York, NY, USA; ${ }^{\mathrm{d}}$ Liège University Hospital CHU, Liège, Belgium; ${ }^{~}$ Radboud University Medical Centre, and Radboud University Nijmegen, Nijmegen, The Netherlands; ${ }^{f}$ Janssen Research \& Development, LLC, Horsham, PA, USA; ${ }^{9}$ Janssen Scientific Affairs, LLC, Horsham, PA, USA; ${ }^{h}$ Siaal Research Center for Family Medicine and Primary Care, Faculty of Health Sciences, Ben-Gurion University of the Negev, Beer Sheva, Israel; 'Clalit Health Services, Tel Aviv, Israel
\end{abstract}

\begin{abstract}
Purpose: To describe the risk of herpes zoster $(\mathrm{HZ})$ in patients with psoriasis and its relation to nonbiologic systemic therapies or biologic treatment.

Materials and methods: Psoriasis Longitudinal Assessment and Registry (PSOLAR) is an international, prospective, registry that follows adult patients with psoriasis eligible to receive non-biologic systemic therapies or biologic therapies. Mutually exclusive therapy cohorts were defined. HZ incident rates were calculated for each therapy cohort and rates between cohorts were compared using hazard ratios (HR) adjusted for potential confounders, in new users and prevalent-exposure patients.

Results: A total of $55 \mathrm{HZ}$ events were identified in 10,469 patients in PSOLAR. The adjusted hazard ratio in the overall study population (new user and prevalent-exposed patients) was 2.22 (95\% Cl: 0.82-5.97; $p=.116)$ for tumor necrosis factor- $\alpha$ (TNF) inhibitors, $2.73(0.98-7.58 ; p=.054)$ for ustekinumab, and 1.04 $(0.20-5.41 ; p=.966)$ for methotrexate versus reference (combined phototherapy, systemic steroids, topical therapy, and immunomodulators other than methotrexate).

Conclusions: Exposure to ustekinumab, TNF- $\alpha$ inhibitors, and methotrexate was not associated with a statistically significant increased risk of HZ. However, HRs were elevated for ustekinumab and TNF- $\alpha$ inhibitors; a larger number of $\mathrm{HZ}$ events would be needed to assess the presence or absence of risk.
\end{abstract}

ARTICLE HISTORY

Received 13 November 2017 Accepted 2 February 2018

\section{KEYWORDS}

Biologics; herpes zoster; psoriasis; PSOLAR; tumor necrosis factor

\section{Introduction}

Herpes zoster $(\mathrm{HZ})$ is a public health concern and is associated with disability and pain, which may become chronic in the form of post-herpetic neuralgia $(1,2)$. In general, $\mathrm{HZ}$ incidence rates range between 4 per 1000 patient years (PY) in the fifth decade of life, and 10 per 1000 patient years in the eighth decade, with a predilection for females $(3,4)$. The lifetime risk of $\mathrm{HZ}$ is estimated at $10-20 \%(5)$.

In rheumatoid arthritis (RA) and inflammatory bowel disease (IBD), data regarding the association of $\mathrm{HZ}$ and treatment with tumor necrosis factor (TNF) inhibitors are contradictory (6). Recent observational studies reported that treatment with TNF inhibitors is associated with increased risk for $\mathrm{HZ}(7-12)$ and more severe $\mathrm{HZ}$ disease $(13,14)$. On the contrary, a study of 407,319 patients with various immune-mediated inflammatory disorders reported no such association, as did other smaller studies $(15,16)$.

Unlike RA or IBD, no association between $\mathrm{HZ}$ and TNF inhibitor treatment has been demonstrated for psoriasis. Two sequential studies from Israel $(17,18)$ based on a large group of patients with psoriasis reported that monotherapy with biologic treatments had a higher incidence of $\mathrm{HZ}$ compared with the controls; however, the difference did not reach statistical significance (19). However, in the second study, which included more than 500,000 PY of follow-up, patients treated with biologics and methotrexate (MTX) showed a statistically significant greater incidence of $\mathrm{HZ}$ compared with patients treated with non-biologic systemic therapies and biologics alone (18).

Given the expanded use of biologics, including mechanisms of action other than TNF inhibition, there is a need for further studies evaluating the association between non-biologic systemic therapy for psoriasis and $\mathrm{HZ}$ risk. Prophylactic vaccination for $\mathrm{HZ}$ is available, and identification of high-risk populations could lead to meaningful clinical intervention. The objective of this investigation was to evaluate the risk for $\mathrm{HZ}$ in a large population with psoriasis exposed to non-biologic systemic therapies or biologic therapies from the Psoriasis Longitudinal Assessment and Registry (PSOLAR) registry (20).

\section{Patients and methods \\ Patients and study design}

This is an observational cohort study of the patients enrolled in PSOLAR. Details of the registry have been previously described (20). PSOLAR is a prospective, international disease-based registry that follows adult patients with psoriasis receiving or eligible to receive conventional non-biologic systemic therapies or biologic agents $(20,21)$. In brief, physicians prescribed treatments for psoriasis based on usual practices of care. Disease activity, psoriasis 
drug utilization patterns, data for comorbidities, and adverse events were captured by the participating physicians at enrollment and at 6-month follow-up visits.

\section{Treatment cohorts}

Information pertaining to the use of psoriasis treatments was collected prospectively and exposure was based on person-time. The following mutually exclusive exposure groups were considered: (1) TNF inhibitors (combined adalimumab, etanercept, infliximab, and golimumab), (2) ustekinumab, (3) MTX, and (4) no biologics/ no MTX. In the TNF inhibitor and ustekinumab groups, patients may have been exposed in the past to other biologic, non-biologic systemic therapies, and photo/topical therapies. Patients with concomitant use of MTX were excluded. Patients in the MTX cohort may have been exposed in the past to a biologic therapy. The no biologics/no MTX exposure group included patients receiving phototherapy, systemic steroids, topical therapy, and immunomodulators other than MTX, with no biologic therapy exposure on their medical record.

\section{Outcomes}

Only the first $\mathrm{HZ}$ episode during the registry follow-up for any given patient was included in the analysis, and episodes were based on physician reporting. All $\mathrm{HZ}$ adverse events captured in PSOLAR are coded to terms in the "Infections and Infestations" system organ class of the Medical Dictionary for Regulatory Activities (version 16.0). The following events representative of $\mathrm{HZ}$ were included: $\mathrm{HZ}, \mathrm{HZ}$ multi-dermatomal, $\mathrm{HZ}$ disseminated, $\mathrm{HZ}$ oticus, $\mathrm{HZ}$ ophthalmic, $\mathrm{HZ}$ iridocyclitis, and $\mathrm{HZ}$ neurological. Information about antiviral medication use and prior $\mathrm{HZ}$ vaccination was not collected.

\section{Statistical analysis}

Demographic and disease characteristics at baseline, as well as medical history and prior treatments, are summarized as means and percentages. The incidence rate of $\mathrm{HZ}$ was calculated as the number of new events per 100 PY of follow-up in each treatment group. Person time (PY) corresponds to the number of years exposed to the group defining medication. The start date of exposure (index date) was the first exposure to a medication on/ during registry participation and ended at the earlier of the date of first $\mathrm{HZ}$ event, reference end date, initiation of another biologic treatment or MTX, 90 days after the last dose of the cohort defining treatment, or the date of the data cutoff (August 23, 2014). The start date of exposure matched the registry enrollment date for patients who were already exposed to a cohort-defining treatment at registry entry (prevalent users). The main analysis (overall population) includes both the new user (incident) population of patients initiating biologic therapy on or after registry entry and the prevalent user population. An additional pre-specified analysis includes only the new user population.

Incidence rates of $\mathrm{HZ}$ were compared between treatment cohorts against the no biologics/no MTX reference cohort using Cox proportional hazard ratios (HR) adjusted for potential prespecified defined confounders (i.e., baseline demographics [i.e., age, gender, ethnicity], baseline disease characteristics [e.g. body mass index, duration of disease], severity of psoriasis, prior treatments, and recent systemic steroid use). Only covariates with a $p$ values $\leq .2$ were retained in the multivariate model. Missing values for covariates were imputed as the mean for continuous variables and the median for categorical covariates. HR are also reported within pre-specified groups (those with diabetes and malignancies) and by age strata.

\section{Results}

\section{Baseline demographic and disease characteristics}

A total of 10,469 patients (24,025 PY) from PSOLAR contributed to this analysis with a median follow-up time of 3.2 years. Baseline characteristics at the time of enrollment in PSOLAR for the overall population were comparable among treatment groups, with a mean age of 49 years. Most patients were white $(83.3 \%)$, and more than half of the patients were overweight $(57.2 \%)$, with a mean body mass index of $30.9 \mathrm{~kg} / \mathrm{m}^{2}$ (Table 1). The mean duration of psoriasis was 17.5 years and mean body surface area involvement was $11.9 \%$.

Overall, $48.5 \%$ of patients $(n=5076)$ received TNF inhibitors, $25.8 \%$ had received ustekinumab $(n=2704), 11.5 \%$ had received MTX $(n=1201)$, and $14.2 \%(n=1488)$ received no biologics/no MTX during participation in the registry; these groups were not mutually exclusive (Table 1). Prior to entering the registry, most patients $(70.4 \%)$ in the overall population had received at least one biologic, $96.9 \%$ had used topical therapy, $63.3 \%$ had used phototherapy, $23.1 \%$ had used systemic steroids, and $46.5 \%$ had used immunomodulators (Table 1). Overall, $73.3 \%$ of patients receiving TNF-inhibitors, $84.6 \%$ receiving ustekinumab, $70.3 \%$ receiving $\mathrm{MTX}$, and $47.8 \%$ receiving no biologics/no MTX remained in the registry at the end of the study follow-up (Figure 1).

\section{Incidence of $\mathrm{HZ}$ in the overall population}

In the overall population, a total of $55 \mathrm{HZ}$ events through 24,025 PY of follow-up were identified across the treatment cohorts (Table 2). Incidence rates/100 PY for each treatment cohort were 0.25 [0.17-0.36] for TNF inhibitors, 0.29 [0.18-0.46] for ustekinumab, 0.14 [0.02-0.49] for MTX, and 0.11 [0.04-0.27] for the no biologics/no MTX control cohort. The adjusted HR for incidence rates of $\mathrm{HZ}$ for each treatment cohort versus the no biologics/no MTX reference cohort were: $2.22(95 \% \mathrm{Cl}: 0.82-5.97 ; p=.116)$ for TNF inhibitors, 2.73 (95\% Cl: 0.98-7.58; $p=.054$ ) for ustekinumab, and 1.04 (95\% Cl: $0.20-5.41 ; p=.966)$ for MTX.

Increasing age was associated with $\mathrm{HZ}(\mathrm{HR}=1.35[95 \% \mathrm{Cl}$ : 1.08-1.68; $p=.008]$ ) (Table 3 ). Other risk factors such as race, obesity, systemic steroid use, psoriasis severity, duration of psoriasis, psoriatic arthritis, and prior history of phototherapy were not found to be predictors of $\mathrm{HZ}$ (Table 3 ).

\section{$H Z$ in the new user population}

In the new user population subset, which was based on fewer events $(n=19)$ among 3561 patients, adjusted incident HRs for each treatment cohort compared with the reference cohort were: 3.66 (95\% Cl: $1.15-11.63 ; p=.028$ ) for TNF inhibitors and 2.69 (95\% Cl: $0.76-9.58 ; p=.126)$ for ustekinumab (data not shown). No $\mathrm{HZ}$ events were reported in the MTX cohort.

\section{Discussion}

We studied a large population-based cohort from the PSOLAR registry comprising 10,469 patients with psoriasis and median follow-up of 3.2 years. It was observed that treatment with TNF inhibitors, ustekinumab, or MTX was not associated with a statistically significant increased risk of $\mathrm{HZ}$, although $\mathrm{HRs}$ for 
Table 1. Baseline demographics and disease characteristics; overall cohort.

\begin{tabular}{|c|c|c|c|c|c|}
\hline & $\begin{array}{c}\text { TNF- } \alpha \text { inhibitors }^{a} \\
(N=5076)\end{array}$ & $\begin{array}{l}\text { Ustekinumab } \\
(N=2704)\end{array}$ & $\begin{array}{c}\text { Methotrexate (MTX) } \\
(N=1201)\end{array}$ & $\begin{array}{c}\text { No biologics/No MTX } \\
(N=1488)\end{array}$ & $\begin{array}{c}\text { All } \\
(N=10,469) \\
\end{array}$ \\
\hline Age (years), $n$ & 5076 & 2704 & 1201 & 1487 & 10,468 \\
\hline Mean \pm SD & $47.9 \pm 13.4$ & $47.3 \pm 13.0$ & $52.3 \pm 13.7$ & $49.9 \pm 15.9$ & $48.5 \pm 13.8$ \\
\hline Men & $2881(56.8)$ & $1601(59.2)$ & $570(47.5)$ & $750(50.4)$ & $5802(55.4)$ \\
\hline White & $4123(81.2)$ & $2357(87.2)$ & $980(81.6)$ & $1263(84.9)$ & $8723(83.3)$ \\
\hline \multicolumn{6}{|l|}{ Weight (kg) } \\
\hline$N$ & 4994 & 2660 & 1190 & 1479 & 10,323 \\
\hline Mean \pm SD & $90.8 \pm 22.9$ & $91.6 \pm 22.5$ & $89.7 \pm 23.1$ & $86.2 \pm 21.3$ & $90.2 \pm 22.7$ \\
\hline \multicolumn{6}{|l|}{ Body mass index $\left(\mathrm{kg} / \mathrm{m}^{2}\right)$} \\
\hline N & 4987 & 2656 & 1190 & 1477 & 10,310 \\
\hline Mean \pm SD & $31.0 \pm 7.1$ & $31.0 \pm 7.0$ & $31.2 \pm 7.5$ & $29.8 \pm 6.8$ & $30.9 \pm 7.1$ \\
\hline Obesity class & 4987 & 2656 & 1190 & 1477 & 10,310 \\
\hline Underweight/Normal (BMI <25) & $952(19.1)$ & $468(17.6)$ & $232(19.5)$ & $346(23.4)$ & 1998 (19.4) \\
\hline Overweight/Obesity class I $(25.0 \leq \mathrm{BMI}<35)$ & $2826(56.7)$ & $1566(59.0)$ & $660(55.5)$ & $846(57.3)$ & $5898(57.2)$ \\
\hline Obesity class II-III (BMI $\geq 35.0)$ & $1209(24.2)$ & $622(23.4)$ & $298(25.0)$ & $285(19.3)$ & 2414 (23.4) \\
\hline \multicolumn{6}{|l|}{ PGA Score } \\
\hline$N$ & 4874 & 2606 & 1147 & 1392 & 10,019 \\
\hline Mean \pm SD & $1.9(1.20)$ & $2.0(1.27)$ & $2.1(1.18)$ & $2.3(1.05)$ & $2.0(1.21)$ \\
\hline \multicolumn{6}{|l|}{ Body Surface Area involvement (\%) } \\
\hline N & 5011 & 2675 & 1197 & 1483 & 10,366 \\
\hline Mean $\pm S D$ & $11.1(17.20)$ & $12.3(17.42)$ & $12.5(18.59)$ & $13.4(16.66)$ & $11.9(17.36)$ \\
\hline \multicolumn{6}{|l|}{ Duration of psoriasis, years } \\
\hline$N$ & 5024 & 2679 & 1186 & 1481 & 10,370 \\
\hline Mean \pm SD & $17.7 \pm 13.1$ & $19.4 \pm 12.6$ & $17.2 \pm 14.4$ & $13.8 \pm 14.3$ & $17.5 \pm 13.4$ \\
\hline \multirow{2}{*}{\multicolumn{6}{|c|}{ Medical history }} \\
\hline & & & & & \\
\hline Cardiovascular $^{\mathrm{b}}$ & $1940(38.2)$ & $1020(37.7)$ & $530(44.1)$ & $534(35.9)$ & $4024(38.4)$ \\
\hline Pulmonary & $741(14.6)$ & 334 (12.4) & $208(17.3)$ & $206(13.8)$ & 1489 (14.2) \\
\hline Psychiatric illness & $1042(20.5)$ & $528(19.5)$ & $298(24.8)$ & $277(18.6)$ & $2145(20.5)$ \\
\hline Hepatic & $237(4.7)$ & $90(3.3)$ & $47(3.9)$ & $49(3.3)$ & $423(4.0)$ \\
\hline Skin cancer & $297(5.9)$ & $115(4.3)$ & $85(7.1)$ & $124(8.3)$ & $621(5.9)$ \\
\hline Malignancies ${ }^{c}$ & $146(2.9)$ & $61(2.3)$ & $75(6.2)$ & $94(6.3)$ & $376(3.6)$ \\
\hline Diabetes mellitus type II & $541(10.7)$ & $311(11.5)$ & $159(13.2)$ & $165(11.1)$ & $1176(11.2)$ \\
\hline Serious infections ${ }^{d}$ & $1308(25.8)$ & $602(22.3)$ & $323(26.9)$ & $312(21.0)$ & $2545(24.3)$ \\
\hline Alcohol use, current & $3299(65.0)$ & $1973(73.0)$ & $604(50.3)$ & $962(64.7)$ & $6838(65.3)$ \\
\hline Smoking, current & $1109(21.9)$ & $751(27.8)$ & $265(22.1)$ & $345(23.2)$ & $2470(23.6)$ \\
\hline \multicolumn{6}{|l|}{ Prior therapy use } \\
\hline Biologic agents & $4413(86.9)$ & $2349(86.9)$ & $613(51.0)$ & $0(0.0)$ & 7375 (70.4) \\
\hline Etanercept & $2819(55.5)$ & $946(35.0)$ & $347(28.9)$ & $0(0.0)$ & 4112 (39.3) \\
\hline Adalimumab & $1990(39.2)$ & $824(30.5)$ & $269(22.4)$ & $0(0.0)$ & $3083(29.4)$ \\
\hline Ustekinumab & $113(2.2)$ & 1856 (68.6) & $90(7.5)$ & $0(0.0)$ & 2059 (19.7) \\
\hline Infliximab & 1063 (20.9) & $341(12.6)$ & $265(22.1)$ & $0(0.0)$ & 1669 (15.9) \\
\hline Golimumab & $16(0.3)$ & $18(0.7)$ & $7(0.6)$ & $0(0.0)$ & $41(0.4)$ \\
\hline Topical therapy & 4950 (97.7) & $2596(96.1)$ & $1170(97.5)$ & $1412(95.0)$ & $10,128(96.9)$ \\
\hline \multicolumn{6}{|l|}{ Phototherapy } \\
\hline Psoralens + UVA & $928(18.3)$ & $565(20.9)$ & $220(18.3)$ & $95(6.4)$ & $1808(17.3)$ \\
\hline UVB & $2285(45.1)$ & $1405(52.0)$ & $494(41.2)$ & $623(41.9)$ & $4807(46.0)$ \\
\hline Systemic steroids & $1256(24.8)$ & $518(19.2)$ & $347(28.9)$ & $290(19.5)$ & $2411(23.1)$ \\
\hline Immunomodulators & $2312(45.6)$ & $1486(55.0)$ & $1012(84.3)$ & $54(3.6)$ & $4864(46.5)$ \\
\hline Methotrexate & 1910 (37.7) & $1205(44.6)$ & $988(82.3)$ & $0(0.0)$ & $4103(39.3)$ \\
\hline Cyclosporine & $811(16.0)$ & $654(24.2)$ & $172(14.3)$ & $34(2.3)$ & $1671(16.0)$ \\
\hline Oral Tacrolimus & $4(0.1)$ & $0(0.0)$ & $0(0.0)$ & $1(0.1)$ & $5(<0.1)$ \\
\hline Mycophenolate mofetil & $13(0.3)$ & $17(0.6)$ & $10(0.8)$ & $1(0.1)$ & $41(0.4)$ \\
\hline Other immunomodulators & $116(2.3)$ & $81(3.0)$ & $36(3.0)$ & $17(1.1)$ & $250(2.4)$ \\
\hline
\end{tabular}

Values are $n(\%)$ unless otherwise indicated.

BMI: body mass index; PGA: Physician's Global Assessment; SD: standard deviation; TNF: tumor necrosis factor; UVA: ultraviolet A; UVB: ultraviolet B.

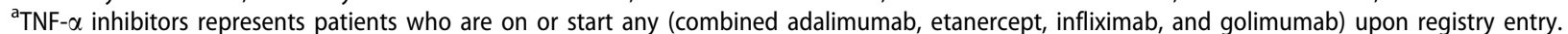

bIncludes atherosclerotic disease, peripheral arterial disease, coronary artery disease, transient ischemic attack/stroke, angina, congestive heart failure, myocardial infarction, hypertension, and hyperlipidemia.

Includes melanoma and other (solid) malignancies.

${ }^{d}$ Serious infections requiring treatment within the last 3 years.

TNF inhibitors and ustekinumab were elevated. As expected, older age was associated with increased risk of $\mathrm{HZ}$; however, systemic steroid use and disease activity were not found to be associated with the risk of $\mathrm{HZ}$ in the overall population studied.

A total of $55 \mathrm{HZ}$ events were identified through 24,025 PY of observation in this large psoriasis cohort, corresponding to an incidence rate of $<3$ per 1000 PY. In the United States' (US) general population, incidence rates for $\mathrm{HZ}$ in patients $>18$ years of age were approximately 3-5 per 1000 PY (22), and these rates increased with age to 7-11 per 1000 PY for those between 60 and 80 years of age, respectively (23). In another study, incidence rates of $\mathrm{HZ}$ were 5.1 and 9.8 per 1000 PY, respectively, among US patients with psoriasis using non-biologic disease-modifying antirheumatic drugs (DMARDs) or those using TNF inhibitors (14). In contrast, the rates of $\mathrm{HZ}$ reported in the PSOLAR registry are lower. Of note, $\mathrm{HZ}$ was not listed as a protocol-specified safety adverse event of interest in PSOLAR, which may have led, in part, to underreporting by registry investigators and accrual of fewer events than expected. 


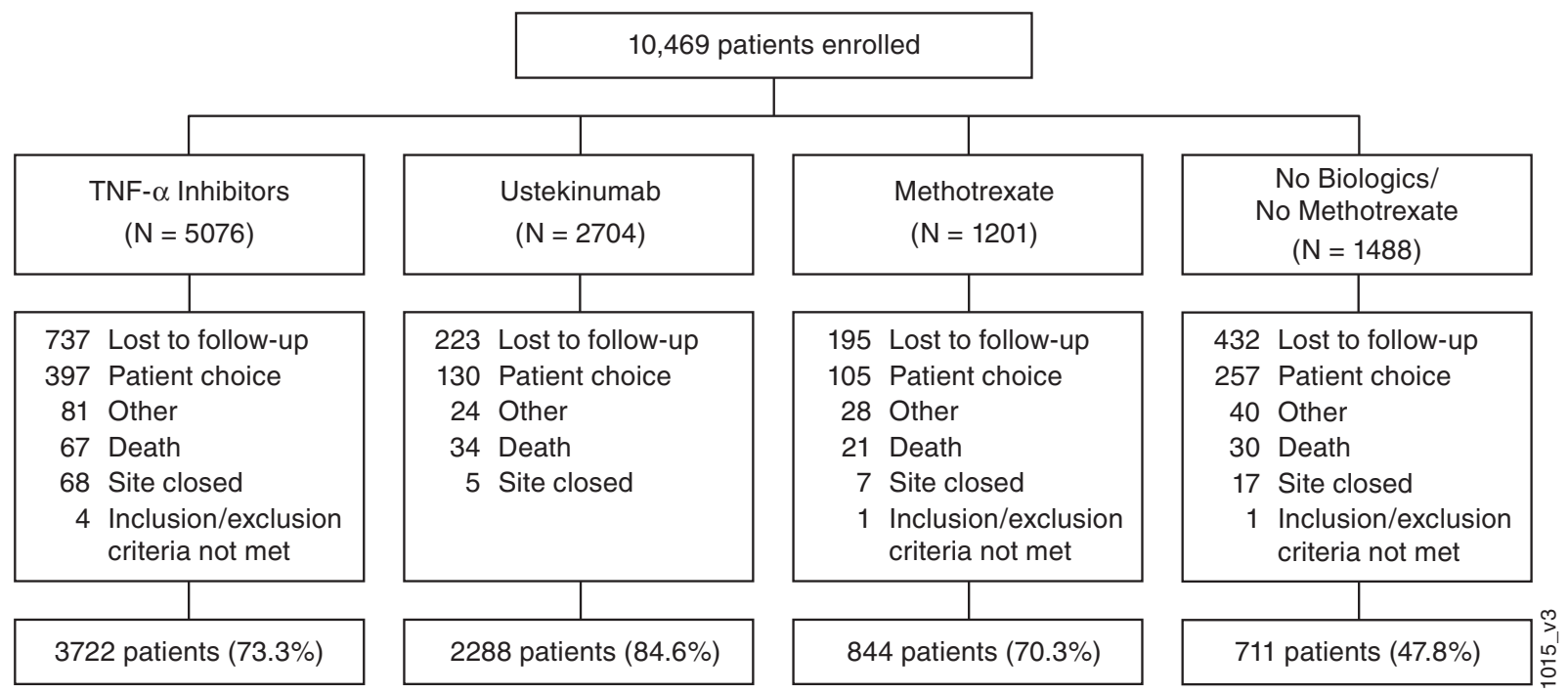

Note: The TNF- $\alpha$ inhibitors cohort represents patients who are on or start any (combined adalimumab, etanercept, infliximab, golimumab) upon registry entry.

Figure 1. Patient disposition; overall population.

Table 2. Incidence rates and adjusted hazard rates of herpes zoster per 100 patient-years; overall cohort.

\begin{tabular}{|c|c|c|c|c|}
\hline & TNF- $\alpha$ inhibitors $^{\mathrm{a}}(N=5076)$ & Ustekinumab $(N=2704)$ & Methotrexate (MTX) $(N=1201)$ & No biologics/no MTX $(N=1488)$ \\
\hline Patient years, $N$ & 11,717 & 6471 & 1463 & 4374 \\
\hline Herpes zoster events, $N$ & 29 & 19 & 2 & 5 \\
\hline Rates $(95 \% \mathrm{Cl})$ & $0.25(0.17,0.36)$ & $0.29(0.18,0.46)$ & $0.14(0.02,0.49)$ & $0.11(0.04,0.27)$ \\
\hline Adjusted hazard ratio $(95 \% \mathrm{Cl})$ & $2.22(0.82,5.97)$ & $2.73(0.98,7.58)$ & $1.04(0.20,5.41)$ & Reference group \\
\hline
\end{tabular}

95\% Cl: $95 \%$ confidence interval. The incidence of adverse events is reported as rate of adverse events per 100 patient-years. Number of patient-years is defined as the number of years exposed to the group defining medication. Exposure starts from first exposure to a medication on/during registry participation and ends at the earlier of the date of first $\mathrm{HZ}$ event, reference end date, initiating another biologic treatment or MTX, 90 days after the last dose of the cohort defining treatment or the date of the annual data cutoff (August 23, 2014). Patient-years: number of days of exposure/365.25. Hazard ratio is derived using Cox proportional model with covariates adjusted.

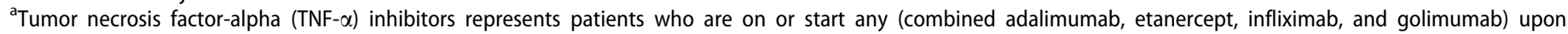
registry entry.

Table 3. Predictors of time to first herpes zoster event; overall cohort.

\begin{tabular}{lrr}
\hline & Adjusted hazard ratio $(95 \%$ Cl) & $p$ value \\
\hline Age/10 years at baseline & $1.35(1.08,1.68)$ & .008 \\
Non-White vs. White & $0.51(0.18,1.43)$ & .199 \\
Overweight/Obesity Class I vs. Underweight/normal $(25<\mathrm{BMI}<35$ vs. $<25)$ at baseline & $0.91(0.41,2.02)$ & .821 \\
Obesity Class II, III versus Underweight/normal (BMI $\geq 35$ versus $<25)$ at baseline & $1.78(0.77,4.10)$ & .177 \\
PGA 2,3 versus PGA 0,1 at baseline & $1.05(0.60,1.83)$ & .866 \\
PGA 4,5 versus PGA 0,1 at baseline & $0.24(0.03,1.78)$ & .161 \\
Duration of psoriasis/5 years at baseline & $1.03(0.93,1.13)$ & .608 \\
History of phototherapy versus no history & $1.31(0.73,2.36)$ & .369 \\
Psoriatic arthritis versus no history & $1.16(0.67,2.03)$ & .590 \\
Time-dependent systemic steroid use in the past 6 months versus no use & $2.59(0.93,7.22)$ & .070 \\
TNF- $\alpha$ inhibitors versus no biologics/no MTX & $2.22(0.82,5.97)$ & .116 \\
Ustekinumab versus no biologics/no MTX & $2.73(0.98,7.58)$ & .054 \\
MTX versus no biologics/no MTX & $1.04(0.20,5.41)$ & .966 \\
\hline
\end{tabular}

95\% Cl: 95\% confidence interval; TNF: tumor necrosis factor; BMI: body mass index; PGA: Physician's Global Assessment; MTX: methotrexate.

The TNF- $\alpha$ inhibitors cohort represents patients who are on or start any (combined adalimumab, etanercept, infliximab, and golimumab) upon registry entry.

Hazard ratio is derived using Cox proportional model with other covariates adjusted; $p$ values are derived from Wald Chi-square test after accounting for other covariates in the Cox model. Only covariates with univariate $p$ values $\leq .2$ were included in this table.

Concomitant topical, phototherapy, or systemic steroid use each represent a time-dependent variable that varies at 6-month intervals prior to the first herpes zoster event and is defined as any use within 183 days of the event date; time-dependent disease activity (PGA) is the nonmissing value from the last visit prior to the first herpes zoster event.

There are very few studies that explore the risk of developing $\mathrm{HZ}$ among patients with psoriasis in relationship to treatment exposure. Evidence from randomized clinical trials are often underpowered to detect differences. An observational cohort study from a US claims database reported no difference between the risk of $\mathrm{HZ}$ in new users of TNF inhibitors and the use of nonbiologic DMARDs (reference group) (adjusted $\mathrm{HR}=0.63[95 \% \mathrm{Cl}$ : $0.28-1.43]$ ) (15). Similarly, a study in Israel also reported no difference among patients receiving phototherapy, MTX, cyclosporine or a single biologic agent alone in comparison to patients not 
receiving non-biologic systemic therapies (18). Nevertheless, that study did report an increase in $\mathrm{HZ}$ incidence with the use of biologics and MTX in combination ( $\mathrm{HR}=1.66$ [95\% Cl 1.08-2.57]).

Our study was consistent with these previous reports (18). However, unlike these previous reports, the HRs for $\mathrm{HZ}$ risk were elevated for biologic therapies (i.e. TNF inhibitors and ustekinumab), albeit not statistically significant findings. Our study design excluded biologic patients receiving concomitant treatment with MTX; therefore, we were unable to confirm the increased risk observed with combined therapy in the Israeli study (18). In a subset of the new-user population, for which we could characterize exposure with more accuracy and adjust for pretreatment variables appropriately, we did observe a significantly increased risk of $\mathrm{HZ}$ among patients receiving TNF inhibitors (adjusted $\mathrm{HR}=3.66$ [95\% Cl: 1.15-11.63]), but the wide Cls make it difficult to interpret the magnitude of risk. The reference group used was heterogenous to increase power; however, the inclusion of non-biologic systemic therapies in this group could have confounded the results. Also, data for TNF inhibitors were pooled; therefore, we did not estimate the potential risk associated with each individual TNF inhibitor.

In this report, increasing age was the only factor that was associated with higher susceptibility to development of $\mathrm{HZ}$. This finding is expected, as the incidence and severity of $\mathrm{HZ}$ are known to increase with age (24). Other known risk factors, such as systemic steroid exposure ( $\mathrm{HR}=2.59$ [95\%Cl: $0.93-7.22, p=.070]$ ), did not reach statistical significance, most likely due to the paucity of $\mathrm{HZ}$ events. Disease severity and various comorbidities associated with psoriasis, similarly did not confer an increased risk of $\mathrm{HZ}$.

A strength of our study is that it utilizes the largest diseasebased psoriasis registry experienced in enrolling and gathering detailed demographic, clinical, and treatment data from patients with median follow-up of 3.2 years. Some limitations of this study design should be considered when interpreting these findings. Lower than expected incidence rates of $\mathrm{HZ}$ may be a result of the low sensitivity to detecting new $\mathrm{HZ}$ events in patients enrolled in PSOLAR and recall bias. Also, previous history of $\mathrm{HZ}$ and vaccination status prior to therapy exposure was not recorded; therefore, this limited the power of the study and its ability to draw conclusions on the relationship of drug therapy and $\mathrm{HZ}$. Additionally, treatment selection bias may exist to some extent; consequently, baseline demography and disease characteristics varied among treatment cohorts. We addressed this limitation by adjusting results for relevant and identifiable confounding factors; nonetheless residual confounding could exist for unmeasured variables. Finally, data regarding dosing adjustments were not captured; therefore, stratification of the results by dose and dose intervals was not performed.

In conclusion, in this real-world global study in patients with psoriasis, treatment with TNF inhibitors, ustekinumab, and MTX did not demonstrate a significant increase in the risk of $\mathrm{HZ}$; however, continued follow-up will be important as more data and events accrue.

\section{Acknowledgements}

The authors would like to thank Kristin Ruley Sharples, PhD, of Janssen Scientific Affairs, LLC (Spring House, PA) and Teresa Tartaglione, PharmD, of Synchrogenix, a Certara Company (Wilmington, DE) for their writing and editorial support.

\section{Disclosure statement}

G. Shalom has no conflicts of interest; L. Naldi has received consultant fees from Abbvie, Eli Lilly, Janssen-CILAG, Menarini, Novartis, Pfizer, and Sanofi; M. Lebwohl is an employee of Mount Sinai, which receives research funds from: Abbvie, Amgen, Boehringer Ingelheim, Celgene, Eli Lilly, Janssen/Johnson \& Johnson, Kadmon, Medimmune/Astra Zeneca, Novartis, Pfizer, and ViDac; A. Nikkels has no conflicts of interest; E.M.G.J. de Jong has received research grants for the independent research fund of the Department of Dermatology of the Radboud University Medical Centre, Nijmegen, the Netherlands (Radboud) from AbbVie, Janssen, and Pfizer; has acted as consultant and/or paid speaker for and/or participated in research sponsored by companies that manufacture drugs used for the treatment of psoriasis including: AbbVie, Amgen, Celgene, Eli Lilly, Janssen, MSD, Novartis, and Pfizer. All funding goes to the independent research fund of "Radboud"; A. D. Cohen has served as a consultant, advisor, or speaker for AbbVie, Dexcel Pharma, Janssen, Novartis, Perrigo, Pfizer, and Rafa; S. Fakharzadeh, K. G. Goyal, B. Srivastava, W. Langholff, and C. Galindo are all employees of Janssen Scientific Affairs, LLC, and own stock in Johnson \& Johnson, of which Janssen is a subsidiary.

\section{Funding}

The PSOLAR study was funded by Janssen Scientific Affairs, LLC, Horsham, PA, USA.

\section{References}

1. Schmader KE, Sloane R, Pieper C, et al. The impact of acute herpes zoster pain and discomfort on functional status and quality of life in older adults. Clin J Pain. 2007;23:490-496.

2. Yawn BP, Saddier P, Wollan PC, et al. A population-based study of the incidence and complication rates of herpes zoster before zoster vaccine introduction. Mayo Clin Proc. 2007;82:1341-1349.

3. Pinchinat $\mathrm{S}$, Cebrián-Cuenca $\mathrm{AM}$, Bricout $\mathrm{H}$, et al. Similar herpes zoster incidence across Europe: results from a systematic literature review. BMC Infect Dis. 2013;13:170.

4. Harpaz R, Ortega-Sanchez IR, Seward JF. Advisory Committee on Immunization Practices (ACIP) Department of Health and Human Services Centers for Disease Control and Prevention (CDC). Prevention of herpes zoster: recommendations of the Advisory Committee on Immunization Practices (ACIP). MMWR Recomm Rep. 2008; 57:1-30.

5. Gnann JW Jr, Whitley RJ. Clinical practice. Herpes zoster. N Engl J Med. 2002;347:340-346.

6. Desai RJ, Thaler KJ, Mahlknecht P, et al. Comparative risk of harm associated with the use of targeted immunomodulators: a systematic review. Arthritis Care Res (Hoboken). 2016;68:1078-1088.

7. Pérez-Sola MJ, Torre-Cisneros J, Pérez-Zafrilla B, et al. Infections in patients treated with tumour necrosis factor antagonists: incidence, etiology and mortality in the BIOBADASER registry. Med Clin (Barc). 2011;137:533-540.

8. Kim SY, Solomon DH. Tumor necrosis factor blockade and the risk of viral infection. Nat Rev Rheumatol. 2010;6: 165-174.

9. Galloway JB, Mercer LK, Moseley A, et al. Risk of skin and soft tissue infections (including shingles) in patients exposed to antitumour necrosis factor therapy: results from the 
British Society for Rheumatology Biologics Register. Ann Rheum Dis. 2013;72:229-234.

10. Smitten AL, Choi HK, Hochberg MC, et al. The risk of herpes zoster in patients with rheumatoid arthritis in the United States and the United Kingdom. Arthritis Rheum. 2007;57:1431-1438.

11. Serac G, Tubach F, Mariette X, et al. Risk of herpes zoster in patients receiving anti-TNF- $\alpha$ in the prospective French RATIO registry. J Invest Dermatol. 2012;132:726-729.

12. Listing J, Strangfeld A, Kary $S$, et al. Infections in patients with rheumatoid arthritis treated with biological agents. Arthritis Rheum. 2005;52:3403-3412.

13. Failla V, Jacques J, Castronovo C, et al. Herpes zoster in patients treated with biologicals. Dermatology (Basel). 2012;224:251-256.

14. Strangfeld A, Listing J, Herzer $P$, et al. Risk of herpes zoster in patients with rheumatoid arthritis treated with anti-TNFalpha agents. JAMA. 2009;301:737-744.

15. Winthrop KL, Baddley JW, Chen L, et al. Association between the initiation of anti-TNF therapy and the risk of herpes zoster. JAMA. 2013;309:887-895.

16. McDonald JR, Zeringue AL, Caplan L, et al. Herpes zoster risk factors in a national cohort of veterans with rheumatoid arthritis. Clin Infect Dis. 2009;48:1364-1371.

17. Dreiher J, Kresch FS, Comaneshter D, et al. Risk of herpes zoster in patients with psoriasis treated with biologic drugs. J Eur Acad Dermatol Venereol. 2012;26:1127-1132.
18. Shalom G, Zisman D, Bitterman $H$, et al. Systemic therapy for psoriasis and the risk of herpes zoster: a 500,000 personyear study. JAMA Dermatol. 2015;151:533-538.

19. Wolfe F, Michaud K, Chakravarty EF. Rates and predictors of herpes zoster in patients with rheumatoid arthritis and noninflammatory musculoskeletal disorders. Rheumatology (Oxford). 2006;45:1370-1375.

20. Papp KA, Strober B, Augustin M, et al. PSOLAR: design, utility, and preliminary results of a prospective, international, disease-based registry of patients with psoriasis who are receiving or are candidates for, conventional systemic treatments or biologic agents. J Drugs Dermatol. 2012;11: 1210-1217.

21. Kimball $A B$, Leonardi $C$, Stahle $M$, et al. Demography, baseline disease characteristics and treatment history of patients with psoriasis enrolled in a multicenter, prospective, diseasebased registry (PSOLAR). Br J Dermatol. 2014;171:137-147.

22. Johnson BH, Palmer L, Gatwood J, et al. Annual incidence rates of herpes zoster among an immunocompetent population in the United States. BMC Infect Dis. 2015;15:502-506.

23. Insinga RP, Itzler RF, Pellissier JM, et al. The incidence of herpes zoster in a United States administrative database. J Gen Intern Med. 2005;20:748-753.

24. Izurieta HS, Wernecke M, Kelman J, et al. Effectiveness and duration of protection provided by the live-attenuated herpes zoster vaccine in the medicare population ages 65 years and older. Clin Infect Dis. 2017;64:785-793. 